\title{
Extracellular Serotonin in the Lateral Hypothalamic Area Is Increased during the Postejaculatory Interval and Impairs Copulation in Male Rats
}

\author{
Daniel S. Lorrain, Leslie Matuszewich, Ross D. Friedman, and Elaine M. Hull \\ Department of Psychology, State University of New York at Buffalo, Buffalo, New York 14260
}

Serotonin (5-HT) is generally inhibitory to masculine sexual behavior. It has been suggested that $5-\mathrm{HT}$ released after ejaculation may promote the sexual quiescence of the postejaculatory interval (PEI). The following experiments were conducted to test (1) whether extracellular 5-HT increases in either the anterior lateral hypothalamic area $\left(\mathrm{LHA}_{\mathrm{A}}\right)$ or the medial preoptic area (MPOA) of male rats after ejaculation; (2) whether increasing 5-HT in these sites, by microinjecting the selective serotonin reuptake inhibitor alaproclate, could inhibit copulatory abilities; and (3) whether copulation deficits produced by alaproclate were attributable to locomotor impairments. The effects of local application of alaproclate on extracellular $5-\mathrm{HT}$ levels in the $\mathrm{LHA}_{\mathrm{A}}$ and the MPOA were also tested. Extracellular serotonin was measured in all experiments using in vivo microdialysis.

Ejaculation was correlated with enhanced 5-HT release from the $\mathrm{LHA}_{\mathrm{A}}$; no 5-HT increases were observed before ejaculation,

Regulation of male sexual behavior by serotonin (5-HT) has been studied in humans, primates, and rodents. Most pharmacological manipulations of 5-HT suggest an inhibitory effect of this neurotransmitter on sexual motivation and performance (for review, see Bitran and Hull, 1987; Gorzalka et al., 1990; Zajecka et al., 1991; Wilson, 1994; Yells et al., 1994). Several brain regions may be involved in mediating these serotonergic effects, including preoptic and hypothalamic structures.

The medial preoptic area (MPOA) in males is a major integrative site for processing sexual information and initiating appropriate sexual responses (Meisel and Sachs, 1994). Because of its importance in the expression of masculine sexual behaviors, 5-HT may mediate inhibitory influences by altering MPOA functioning. Microinjection of 5-HT into the MPOA of male rats has been shown to impair sexual activity (Verma et al., 1989; Fernandez-Guasti et al., 1992). Furthermore, results from ex vivo and in vivo analysis of 5-HT activity in the POA have led to the suggestion that 5-HT may be released in this area after ejaculation and may promote the postejaculatory interval (PEI). Levels of the main metabolite of 5-HT, 5-hydroxyindoleacetic acid (5HIAA), were higher in tissue dissected from animals killed after

Received July 21, 1997; revised Sept. 8, 1997; accepted Sept. 18, 1997.

This research was supported by National Institute of Mental Health Grant MH40826 to E.M.H. We thank John J. Panos for assistance with the figures.

Correspondence should be addressed to Dr. Elaine M. Hull, Department of

Psychology, State University of New York at Buffalo, Buffalo, NY 14260.

Dr. Lorrain's present address: Department of Psychiatry, University of Chicago, MC 3077, 5841 South Maryland Avenue, Chicago, IL 60637.

Dr. Matuszewich's present address: Department of Psychiatry, Case Western

Reserve University, 11100 Euclid Avenue, Cleveland, OH 44106-5000.

Copyright (C) 1997 Society for Neuroscience $0270-6474 / 97 / 179361-06 \$ 05.00 / 0$ and levels were decreased toward basal values during a subsequent copulatory series. Elevating $5-\mathrm{HT}$ in the $\mathrm{LHA}_{\mathrm{A}}$ by microinjecting alaproclate inhibited copulation by increasing the latency to mount, intromit, and ejaculate. This inhibition did not result from nonspecific locomotor impairments. In the MPOA, 5-HT release remained stable throughout copulation, and microinjecting alaproclate into this site did not significantly alter sexual behavior.

These data support the large body of evidence suggesting that $5-\mathrm{HT}$ is inhibitory to masculine sexual behavior. Furthermore, the $\mathrm{LHA}_{\mathrm{A}}$, but not the MPOA, may be one site responsible for serotonergic inhibition of copulation during the $\mathrm{PEI}$.

Key words: serotonin; lateral hypothalamic area; medial preoptic area; copulation; postejaculatory interval; microdialysis; male rats

they had ejaculated compared with control animals that had not ejaculated (Mas et al., 1987). Subsequent in vivo microdialysis experiments resulted in similar findings; 5-HIAA increased in dialysate collected from the preoptic area after ejaculation (Fumero et al., 1994; Mas et al., 1995). Because of detection limits, however, 5-HT itself was not measured in those experiments.

Lateral regions of the hypothalamus may also be involved in mediating serotonergic effects on copulation. Stimulating the lateral hypothalamic area (LHA) can induce behavioral activation, including grooming, eating, drinking, and copulation, depending on the surrounding environmental conditions (Glickman and Schiff, 1967; Wayner et al., 1981). Serotonin release, on the other hand, may suppress some of these behaviors. Microinjecting 5-HT agonists into the LHA decreased food intake, and 5-HT release increased in this area during food consumption; this release may potentiate meal termination (Morley et al., 1985; Schwartz et al., 1989; Aoyagi et al., 1992). These findings suggest that LHA 5-HT can inhibit at least one motivated behavior; whether others, such as copulation, may be influenced similarly remains to be tested. Preliminary in vivo experiments in this laboratory showed that 5-HT release increases in the anterior LHA $\left(\mathrm{LHA}_{\mathrm{A}}\right)$ of male rats after ejaculation but not during noncontact exposure to an estrous female or during active copulation.

The present investigation used in vivo microdialysis and pharmacological behavioral tests to characterize the role of endogenous 5-HT in both the $\mathrm{LHA}_{\mathrm{A}}$ and the MPOA in regulating male rat sexual behavior. Results from these experiments suggest that 5-HT is released in the $\mathrm{LHA}_{\mathrm{A}}$, but not the MPOA, and that it may facilitate postejaculatory quiescence in the male rat. 


\section{MATERIALS AND METHODS}

Subjects. Adult male Long Evans/Blue Spruce rats (300-350 gm) were housed individually in large plastic cages in a climate-controlled room with lights off at 11 A.M. and on at 9 P.M. Food and water were available ad libitum. Subjects were weighed daily to check their health and to accustom them to handling. Ovariectomized, hormone-replaced females used in sexual behavior tests were housed in a separate room under similar conditions. After a 1 week adaptation period after their arrival, males were given sexual experience by introducing a female brought into estrus by subcutaneous estradiol benzoate injection $(20 \mu \mathrm{g})$ at $-48 \mathrm{hr}$ Three $30 \mathrm{~min}$ exposures to a female, separated by $4 \mathrm{~d}$, were allowed. During the third session, animals were observed for their sexual ability. All animals copulated to ejaculation.

Intracranial implants. Implantation of guide cannulae for microdialysis and microinjection was performed on subjects deeply anesthetized with ketamine hydrochloride $(50 \mathrm{mg} / \mathrm{kg})$ and xylazine hydrochloride $(4 \mathrm{mg}$ / $\mathrm{kg}$ ) and placed into a Kopf stereotaxic frame (incisor bar at $+5.0 \mathrm{~mm}$ ). Subjects in each experimental condition received $15 \mathrm{~mm}, 23$ gauge thin-wall stainless steel guide cannulae. Coordinates (in $\mathrm{mm}$ ) for the $\mathrm{LHA}_{\mathrm{A}}$ were anteroposterior (AP), +1.3; mediolateral (ML), +1.5 (unilateral) or \pm 1.5 (bilateral); and dorsoventral (DV), -7.2 ; coordinates for the MPOA were AP, +2.2 ; ML, +0.3 ; and $\mathrm{DV},-6.2$. An obturator fashioned from 27 gauge tubing, ending flush with the guide cannula, was inserted into each cannula after surgery to prevent entry of foreign objects. Subcutaneous injections of the antibiotic gentamicin were used to aid recovery.

Apparatus. Concentric microdialysis probes were constructed in the laboratory. A 27 gauge thin-wall stainless steel tube was fitted with a dialysis membrane [18,000 Da cutoff, $210 \mu \mathrm{m}$ outer diameter (o.d.); Spectra-Por] at one end and a $3 \mathrm{~cm}$ piece of polyethylene (PE) 20 tubing at the other end to serve as the inlet for the perfusion medium. The dialysis membrane was glued in place and plugged with waterproof epoxy. A $1 \mathrm{~mm}$ active dialyzing surface was maintained. A $20 \mathrm{~cm}$ length of silica capillary tubing [125 $\mu \mathrm{m}$ o.d., $50 \mu \mathrm{m}$ inner diameter (i.d.); Polymicro Technologies] threaded down into the dialysis tube served as the outlet for the perfusion medium. Samples were collected into $250 \mu \mathrm{l}$ centrifuge tubes and injected, within $1 \mathrm{hr}$, onto a capillary column for 5-HT analysis. The dialysis perfusion medium was a modified Ringer's solution (in mM: $138 \mathrm{NaCl}, 2.7 \mathrm{KCl}$, and $1.2 \mathrm{CaCl}_{2}, \mathrm{pH} 7.0$ ). Flow was controlled by a Harvard model 22 syringe infusion pump.

Serotonin concentrations were measured from dialysis samples using HPLC with electrochemical detection (Fig. 1). Each sample was loaded manually into a Rheodyne injector valve. A $500 \mathrm{nl}$ volume was delivered to an LC Packings C18 reverse-phase capillary column $(0.3 \mathrm{~mm}$ i.d. $\times 5.0$ $\mathrm{cm}$ long) using a mobile phase consisting of (in mM): 30 citric acid, 50 sodium acetate, $0.027 \mathrm{Na}_{2}$-EDTA, and 0.25 octyl sodium sulfate, with $2.5 \%$ acetonitrile and $0.2 \%$ tetrahydrofuran $(\mathrm{v} / \mathrm{v}), \mathrm{pH}$ 3.6. A Gilson model 307 pump was used to circulate the mobile phase. Operating at 0.5 $\mathrm{ml} / \mathrm{min}$ and equipped with an Acurate flow splitter (LC Packings), the pump delivered $6 \mu \mathrm{l} / \mathrm{min}$ to the column. Serotonin was detected electrochemically with an Antec microcell $(11 \mathrm{nl})$ detector using a glassy carbon working electrode maintained at a potential of $+0.7 \mathrm{~V}$ relative to a $\mathrm{Ag} / \mathrm{AgCl}$ reference electrode.

Locomotor test arenas consisted of a plastic cage, similar to the subject's home cage $(55.3 \times 35.6 \times 35.6 \mathrm{~cm})$, lined with fresh bedding. A grid, fabricated from black 20 gauge electrical wire, resulting in $10.2 \times$ $10.2 \mathrm{~cm}$ squares, was placed on top of the test cage and was used to quantify forward locomotion. A video camera was placed directly over the test arena to record the animal's behaviors. Locomotor activity was later scored by viewing the videotape.

Experimental procedures. Experiments $1 \mathrm{a}\left(\mathrm{LHA}_{\mathrm{A}}\right)$ and $1 \mathrm{~b}$ (MPOA) compared 5-HT release during different copulatory events, using in vivo microdialysis. Sexually experienced males were used $\left(n=7\right.$ for $\mathrm{LHA}_{\mathrm{A}}$, $n=16$ for MPOA). Dialysate flowed at $0.5 \mu \mathrm{l} / \mathrm{min}$, and samples were collected in $6 \mathrm{~min}$ intervals (yielding $3 \mu \mathrm{l}$ ). After baseline collection, an estrous female was placed just above the male's test arena inside a wire mesh cage for a 12 min period. The female was then placed into the male's arena, and free copulation was allowed until four ejaculations occurred. During this time samples were divided into those collected during active copulation and those collected during PEIs. After the fourth ejaculation, females were removed, and one (MPOA group) or four ( $\mathrm{LHA}_{\mathrm{A}}$ group) postcopulatory samples were collected, one sample every $30 \mathrm{~min}$.

Experiments $2 \mathrm{a}$ and $2 \mathrm{~b}$ tested the effects of increasing 5-HT in the $\mathrm{LHA}_{\mathrm{A}}$ and the MPOA on copulation. Subjects received either bilateral cannulae aimed at the $\mathrm{LHA}_{\mathrm{A}}(n=12)$ or a unilateral cannula aimed at the MPOA $(n=16)$. After a $7 \mathrm{~d}$ recovery period and a postoperative copulatory baseline test to assure normal copulatory abilities, males were given weekly 30 min copulation tests with drug microinjected immediately before behavioral testing. All subjects received each drug condition in a counterbalanced manner. Microinjections were accomplished by removing the cannula obturator and replacing it with an injection cannula $18 \mathrm{~mm}$ in length. Subjects received $0.0,10.0$, or $20.0 \mu \mathrm{g}$ of alaproclate (Research Biochemicals, Natick, MA) dissolved in $1.0 \mu \mathrm{l}$ of saline, injected at a rate of $0.5 \mu \mathrm{l} / \mathrm{min}$; the injection cannula was left in place for an additional $60 \mathrm{sec}$. The $\mathrm{LHA}_{\mathrm{A}}$ group received $0.5 \mu \mathrm{l} / \mathrm{cannula}$, and the MPOA group received $1 \mu \mathrm{l}$ into their single cannula. The obturators were replaced, the male was taken into a test room dimly illuminated with red light, and an estrous female was introduced for a $30 \mathrm{~min}$ copulation test. The following behavioral parameters were recorded: mount, intromission, and ejaculation latencies; numbers of mounts, intromissions, and ejaculations; and postejaculatory interval. Mount and intromission latencies were measured from the introduction of the female into the dialysis arena. Ejaculation latency was defined as the interval between the first intromission and the ensuing ejaculation. Postejaculatory interval was defined as the interval between the ejaculation and the succeeding intromission.

Experiment 3 tested potential locomotor effects resulting from the drug treatment used in Experiment 2a. Twelve subjects received bilateral guide cannulae aimed at the $\mathrm{LHA}_{\mathrm{A}}$. After a 1 week recovery period, animals were randomly assigned to one of two treatment groups and microinjected with the appropriate concentration of alaproclate $(0.0$ or $20.0 \mu \mathrm{g}$ of alaproclate dissolved in $1.0 \mu \mathrm{l}$ of saline). Immediately after microinjection, subjects were placed into a test arena and then scored for locomotor activities for a $12 \mathrm{~min}$ period. The following behavioral parameters were scored: number of lines crossed (defined as the entire head crossing a line of one of the grids), number of rearings, and time spent grooming.

Experiments $4 \mathrm{a}$ and $4 \mathrm{~b}$ generated estimates of extracellular 5-HT levels in the $\operatorname{LHA}_{\mathrm{A}}(n=12)$ and MPOA $(n=9)$ before and during alaproclate administration using in vivo microdialysis. Dialysate flowed at a rate of $0.5 \mu \mathrm{l} / \mathrm{min}$, and samples were collected in $10 \mathrm{~min}$ intervals (yielding $5 \mu \mathrm{l}$ ). After a stable baseline was established, the dialysate was exchanged for one containing a $0.978,39.107$, or $78.214 \mathrm{~mm}$ alaproclate solution $(0.250,10.0$, or $20.0 \mu \mathrm{g} / \mu \mathrm{l}$, respectively), which was perfused for $20 \mathrm{~min}$. A single dialysate sample was collected during the $10-20 \mathrm{~min}$ period of perfusion; the $10 \mathrm{~min}$ delay allowed for dead volume of the microdialysis probe. Four animals from the $\mathrm{LHA}_{\mathrm{A}}$ group and three from the MPOA group were chosen randomly, and 5-HT concentrations in their final baseline sample, before drug perfusion, were used to calculate basal 5-HT levels.

Estimated basal extracellular values for 5-HT were obtained by a calibration curve established using samples collected from a dialysis probe in vitro (corrected for probe recovery). Briefly, a probe was connected to an infusion pump with a piece of PE 20 plastic tubing. Ringer's solution was pumped through the probe at $0.5 \mu \mathrm{l} / \mathrm{min}$. The tip of the probe was submersed in a $0.0,56.8,113.6$, and $227.3 \mathrm{~nm}$ solution of 5-HT, maintained at a temperature of $37^{\circ} \mathrm{C}$ using a water bath. Three 10 min samples were collected from each of the 45 -HT concentrations and were used to create the calibration curve for 5-HT. Samples collected from the animals were compared with this curve to provide estimated values for extracellular 5-HT levels during alaproclate perfusion. In addition, in vitro recovery values were calculated for five randomly selected probes. Probes were immersed in a solution containing $20 \mathrm{pg} / \mu \mathrm{l}$ 5-HT, maintained at $37^{\circ} \mathrm{C}$. Ringer's solution was pumped through the probes at $0.5 \mu \mathrm{l} / \mathrm{min}$; 6 min samples were collected, and 5-HT concentrations from the probe were compared with that of the bath. Average in vitro recovery was $24.7 \pm 0.8 \%$; the range of recoveries was $22.5-26.5 \%$.

Histology. After completion of each experiment, subjects were deeply anesthetized with an injection of Somlethol and decapitated. Their brains were rapidly removed, frozen, and sectioned using a cryostat. Sections $(40 \mu \mathrm{m})$ were collected and mounted onto glass slides, stained with cresyl violet, coverslipped, and examined for proper placement of guide cannulae. Only those subjects with probes located in the intended brain region were used for statistical analysis.

Statistics. For Experiments 1a and 1b, 5-HT content in dialysate (expressed as a percentage of the mean of the last three baseline peak heights) was compared across the final baseline, estrous female exposure, two active copulation intervals, four postejaculatory intervals, and a $2 \mathrm{hr}$ $\left(\mathrm{LHA}_{\mathrm{A}}\right)$ or $0.5 \mathrm{hr}(\mathrm{MPOA})$ postcopulation interval using one-way re- 


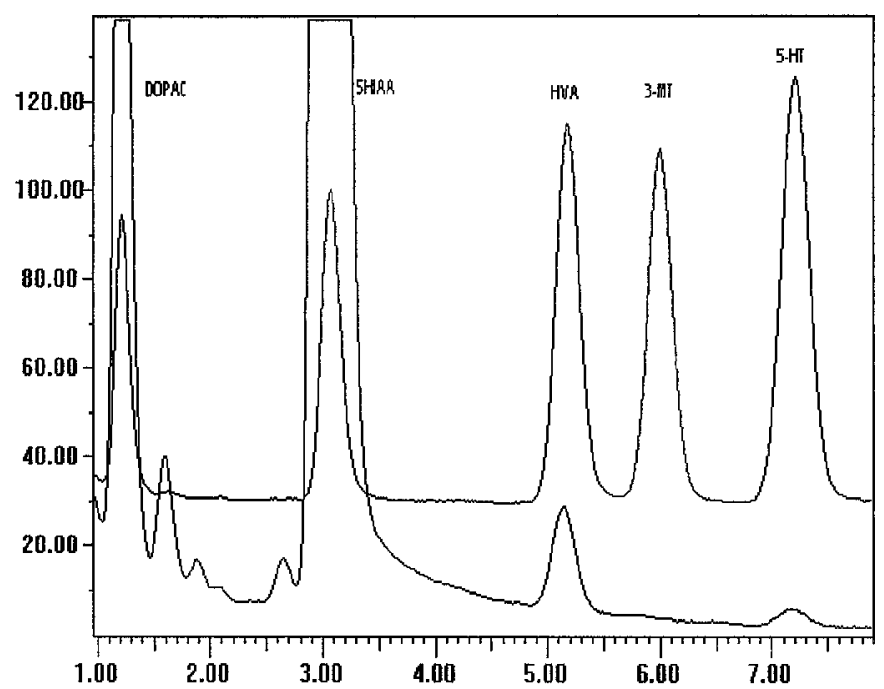

Figure 1. Chromatogram showing a dialysate sample from the $\mathrm{LHA}_{\mathrm{A}}$ (bottom trace) and a mixture of standards (top trace) for (1) dihydroxyphenylacetic acid (DOPAC), (2) 5-HIAA, (3) homovanillic acid (HVA), (4) 3-methoxytyramine (3-MT), and (5) 5-HT. The concentrations of the standards were $4 \mathrm{pg} / \mu \mathrm{l}(2 \mathrm{pg} / 0.5 \mu \mathrm{l}$ injected onto the column).

peated measures ANOVA, followed by Newman-Keuls multiple comparisons tests. Samples collected during active copulation in the second and third copulatory series were not analyzed, because most animals ejaculated before a full 6 min sample could be collected.

For Experiments $2 \mathrm{a}$ and $2 \mathrm{~b}$, copulation latencies and frequencies were compared between the drug conditions using a one-way repeated measures ANOVA, followed by Newman-Keuls multiple comparisons tests For Experiment 3, locomotor activities were compared between subjects receiving vehicle $(0.0 \mu \mathrm{g})$ or $20 \mu \mathrm{g}$ of alaproclate, using a $t$ test. For Experiments $4 \mathrm{a}$ and $4 \mathrm{~b}, 5-\mathrm{HT}$ levels were compared between the drug conditions using a one-way repeated measures ANOVA, followed by Newman-Keuls multiple comparisons tests.

\section{RESULTS}

\section{Experiment 1a: 5-HT release in the $\mathrm{LHA}_{\mathrm{A}}$ during copulation}

In vivo microdialysis revealed that extracellular 5-HT in the $\mathrm{LHA}_{\mathrm{A}}$ was affected by behavioral condition $\left(F_{(12,72)}=4.15 ; p<\right.$ 0.001 ) (Fig. 2). Significant increases were observed only in those samples collected during the second and third PEIs, compared with baseline, precopulatory female exposure, and the first sample of active copulation $(p<0.05)$. The third series PEI sample was also higher than the fourth series active copulation sample $(p<0.05)$. No significant change from baseline was observed for samples collected during non-PEI intervals. A second ANOVA, performed on data collapsed into five behavioral categories, again detected a significant overall effect for event $\left(F_{(4,24)}=10.5 ; p<\right.$ 0.00005 ) (Fig. 2, inset). Post hoc comparisons showed that 5-HT concentrations from samples collected during postejaculatory intervals were increased significantly compared with baseline, precopulation estrous female exposure, active copulation, and postcopulation values $(p<0.05)$.

\section{Experiment 1b: 5-HT release in the MPOA during copulation}

No changes in extracellular 5-HT levels were observed in dialysate collected from probes located in the MPOA during any aspect of male rat sexual behavior $\left(F_{(9,79)}=1.65 ; p=\right.$ 0.114) (Fig. 3).

\section{Experiment 2a: effects of increasing 5-HT in the LHA on copulatory behavior}

Microinjection of alaproclate $(n=12)$ dose-dependently impaired copulatory performance. All of the subjects in the $0.0 \mu \mathrm{g}$ condition copulated to ejaculation. In the $10.0 \mu \mathrm{g}$ condition, only 10 subjects mounted, 9 intromitted, and 7 reached ejaculation. In the $20.0 \mu \mathrm{g}$ condition, 9 subjects mounted, 8 intromitted, and 8 ejaculated. Subjects that did not copulate were assigned latencies equivalent to the test duration (1800 sec). Only the first copulatory series was used for statistical analysis. An overall ANOVA detected a significant effect for treatment on all latencies (mount latency, $F_{(2,22)}=4.89 ; p<0.05$; intromission latency, $F_{(2,22)}=$ $6.86 ; p<0.01$; and ejaculation latency, $\left.F_{(2,22)}=7.72 ; p<0.01\right)$ (Table 1). Post hoc comparison tests revealed that the $20.0 \mu \mathrm{g}$ group had significantly longer mean latencies for all three behaviors when compared with the $0.0 \mu \mathrm{g}$ group. Mean intromission and ejaculation latencies after the $10.0 \mu \mathrm{g}$ dose were also increased significantly. No other behavioral parameters were significantly altered.

\section{Experiment 2b: effects of increasing 5-HT in the MPOA on copulatory behavior}

From animals with correct cannula placement $(n=16)$, no significant change of any behavioral parameter was observed under the three drug conditions. Mean latency to mount, intromit, and ejaculate increased with alaproclate, but the differences did not reach significance. The latencies $( \pm \mathrm{SE})$ for the first copulatory series are given in Table 1.

\section{Experiment 3: effects of $\mathrm{LHA}_{\mathrm{A}}$ alaproclate microinjection on locomotor activity}

Two groups of six subjects were used to compare locomotor activity during a 12 min period after drug administration. No significant change in the mean number of lines crossed or rearings occurred between subjects receiving 0.0 and $20.0 \mu \mathrm{g}$ of alaproclate (Fig. 4A,B). However, alaproclate increased the average time spent in grooming behavior $\left(t_{(10)}=-3.52 ; p<0.01\right.$ ) (Figure $4 C$ ). Facial, body, and genital grooming behaviors were pooled into a single time analysis; however, facial grooming was almost exclusively displayed.

\section{Experiments 4a and 4b: extracellular levels of $5-\mathrm{HT}$ in the LHA $_{A}$ and MPOA after alaproclate perfusion}

Extracellular 5-HT increased in a dose-dependent manner after alaproclate perfusion into the $\operatorname{LHA}_{\mathrm{A}}\left(F_{(3,12)}=15.7 ; p<0.001\right)$ and into the $\operatorname{MPOA}\left(F_{(3,8)}=8.79 ; p<0.01\right)$ (Table 2$)$. The basal extracellular concentration of 5-HT in the $\mathrm{LHA}_{\mathrm{A}}$ was estimated to be $1.6 \pm 0.1 \mathrm{~nm}$ and in the MPOA was $1.4 \pm 0.1 \mathrm{~nm}$.

\section{DISCUSSION}

Consistent with previous reports (for review, see Bitran and Hull, 1987; Wilson, 1994), the present experiments show that 5-HT has an inhibitory role in the control of masculine sexual behavior and may regulate the PEI. Extracellular 5-HT concentrations in samples collected from probes placed into the $\mathrm{LHA}_{\mathrm{A}}$ were increased after ejaculation (during the PEI). There were no increases observed during exposure to an estrous female behind a perforated barrier or during active copulation. Furthermore, alaproclate microinjected into the $\mathrm{LHA}_{\mathrm{A}}$ increased extracellular 5-HT and slowed copulation by increasing mount, intromission, and ejaculation latencies. The increased mount and intromission latencies suggest that 5-HT in the $\mathrm{LHA}_{\mathrm{A}}$ mimics the PEI (delays the onset of copulation). However, ejaculation latency was also 


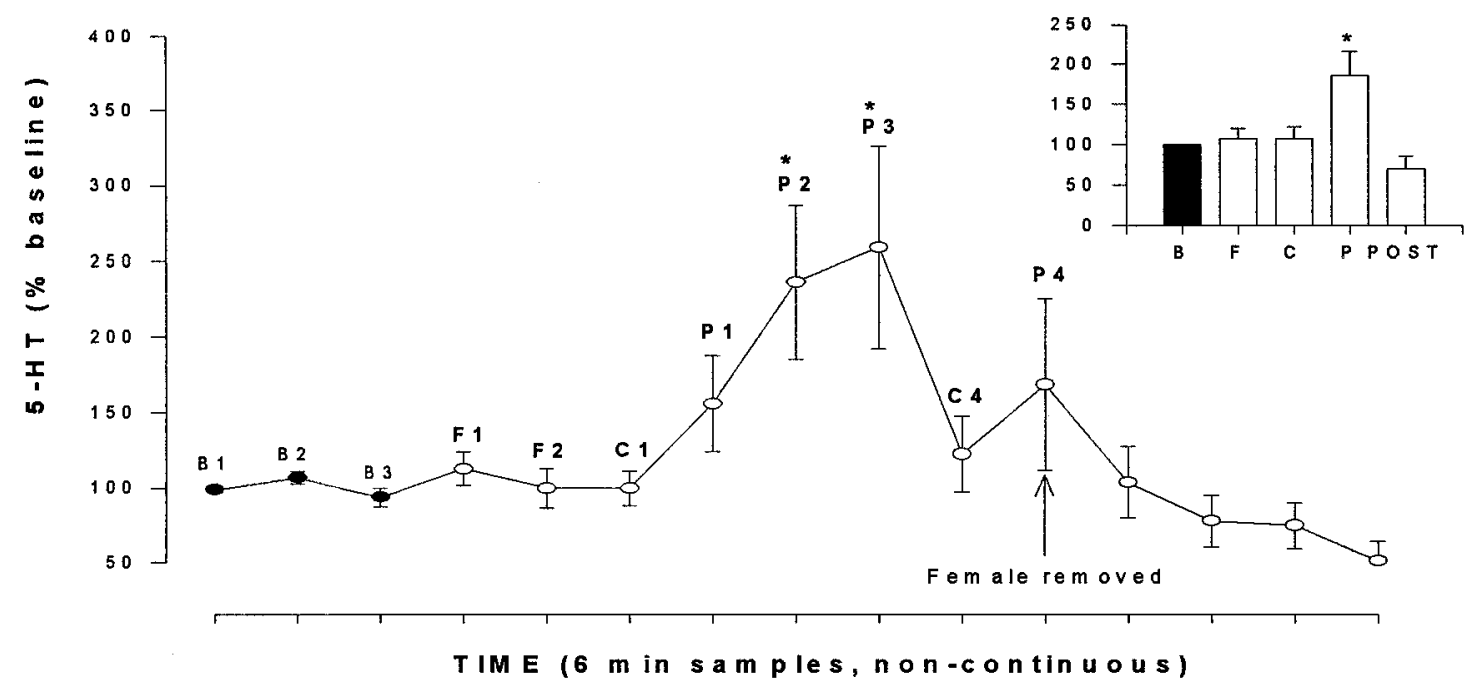

Figure 2. Temporal changes in dialysate concentrations of serotonin (5-HT) collected from the LHA $_{\mathrm{A}}$ of seven subjects during copulatory activities. Each data point represents the mean $\pm \mathrm{SE}$ for 6 min samples collected during baseline $(B)$, in the presence of an estrous female $(F)$, during copulation $(C)$, during the postejaculatory interval $(P)$, and after the female was removed (expressed as a percentage of baseline 5-HT levels). Four samples were analyzed after removal of the female at 30 min intervals. Serotonin levels were increased during the second $(P 2)$ and third $(P 3)$ PEI; ${ }^{*} p<0.05$ versus final baseline $(B)$, female behind barrier $(F)$, and the first active copulation series $(C 1)$. Levels during the third PEI were also significantly greater compared with series 4 active copulation $(C 4)$. Samples collected during the second and third copulation series were not analyzed, because most animals ejaculated before a full 6 min sample could be collected. The summary graph (inset) represents the mean \pm SE for data from the 15 sample periods collapsed into five groups, based on behavioral condition. Samples collected during PEIs $(P)$ show enhanced 5 -HT concentrations; ${ }^{*} p<0.05$ versus $B$, $F, C$, and postcopulation $(P O S T)$. Basal extracellular concentrations in the $\mathrm{LHA}_{\mathrm{A}}$ were estimated to be $1.6 \pm 0.1 \mathrm{nM}$.

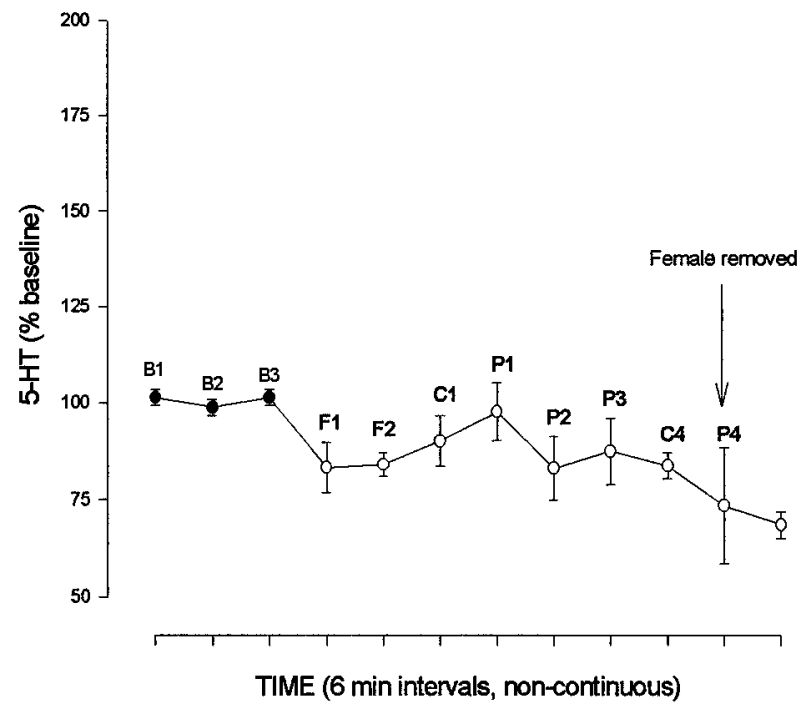

Figure 3. Temporal changes in dialysate concentrations of 5-HT collected from the MPOA of 16 subjects during copulatory activities. One sample was collected 30 min after removal of the female. Each data point represents the mean $\pm \mathrm{SE}$ from 6 min sampling intervals. No change in 5-HT release was observed during the sampling periods. Basal extracellular concentrations of 5 -HT in the MPOA are estimated to be $1.4 \pm 0.1 \mathrm{nM}$.

increased; ejaculation latency is the interval from the first intromission to ejaculation. In other words, impairment was observed even after the animal had begun to copulate. Electrical stimulation of the LHA has been reported to elicit stimulus-bound ejaculations (Singh et al., 1996). Therefore, 5-HT in the LHA $_{A}$ may inhibit neurons that would normally contribute to ejaculation, in addition to promoting sexual quiescence. SSRIs in humans have been reported to interfere with orgasm (Kline, 1989;
Table 1. Effects of alaproclate microinjection on copulation

\begin{tabular}{lrlcc}
$\begin{array}{l}\text { Brain } \\
\text { region }\end{array}$ & $\begin{array}{l}\text { Dose } \\
(\mu \mathrm{g} / \mu \mathrm{ll})\end{array}$ & $\mathrm{ML}$ & $\mathrm{IL}$ & \multicolumn{1}{c}{$\mathrm{EL}$} \\
\hline LHA $_{\mathrm{A}}$ & 0.0 & $166.3 \pm 50.5$ & $315.9 \pm 75.9$ & $450.5 \pm 50.4$ \\
& 10.0 & $548.2 \pm 186.7$ & $859.2 \pm 199.4^{*}$ & $1104.3 \pm 185.4^{*}$ \\
& 20.0 & $849.2 \pm 195.6^{*}$ & $1196.0 \pm 176.1^{*}$ & $1088.2 \pm 182.2^{*}$ \\
MPOA & 0.0 & $251.9 \pm 97.7$ & $384.6 \pm 117.2$ & $793.3 \pm 133.8$ \\
& 10.0 & $337.3 \pm 115.5$ & $525.1 \pm 130.9$ & $680.8 \pm 120.4$ \\
& 20.0 & $457.8 \pm 134.9$ & $722.4 \pm 158.6$ & $889.8 \pm 146.2$
\end{tabular}

Values are means \pm SE for mount, intromission, and ejaculation latencies (ML, IL, and EL, respectively) from 12 subjects $\left(\mathrm{LHA}_{\mathrm{A}}\right.$ group) and 16 subjects (MPOA group) after three doses of alaproclate microinjected bilaterally into the $\mathrm{LHA}_{\mathrm{A}}$ or unilaterally into the MPOA. The 10 and $20 \mu \mathrm{g}$ doses significantly increased latencies for behavioral parameters when microinjected into the $\mathrm{LHA}_{\mathrm{A}}$, compared with the $0.0 \mu \mathrm{g}$ group. No significant changes in mean latencies were observed when alaproclate was microinjected into the MPOA.

$* p<0.05$ versus $0.0 \mu \mathrm{g}$.

Herman et al., 1990; Zajecka et al., 1991). The LHA may be one site at which SSRIs inhibit orgasm, perhaps in addition to the nucleus paragigantocellularis in the ventral medulla (Yells et al., 1994). It is not clear which 5-HT receptor subtypes mediate these effects. However, systemic injections of a 5- $\mathrm{HT}_{2}$ agonist (Foreman et al., 1989) and intracranial injections of a $5-\mathrm{HT}_{1 \mathrm{~B}}$ agonist (Fernandez-Guasti et al., 1992) have impaired copulatory ability of male rats.

The present findings do not support an inhibitory role of 5-HT in the MPOA of male rats. Previous studies had suggested that 5-HT may act in the MPOA to inhibit both appetitive and consummatory aspects of copulation. Specifically, injections of 5-HT into the MPOA of male rats abolished ejaculation and decreased pursuit behaviors (Verma et al., 1989; FernandezGuasti et al., 1992). Furthermore the main metabolite of 5-HT, 5-HIAA, increased significantly in the preoptic area after ejacu- 

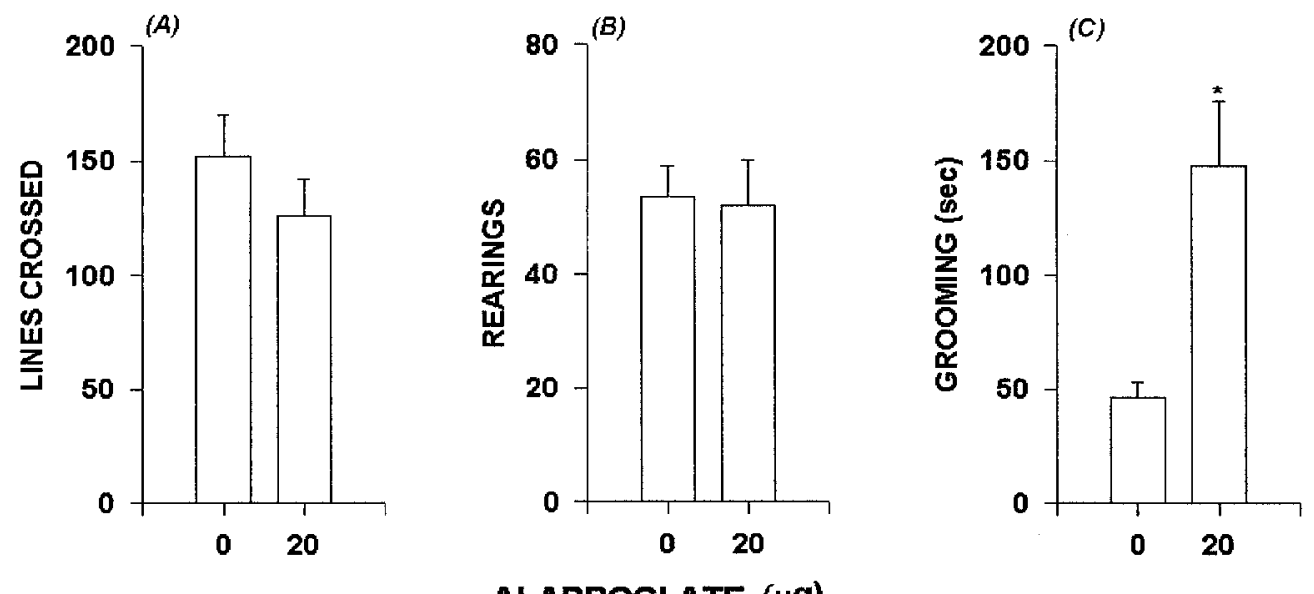

Figure 4. Mean \pm SE for locomotor activities after 0.0 or $20.0 \mu \mathrm{g}$ of bilateral alaproclate microinjections into the LHA $\mathrm{A}_{\mathrm{A}}$ of 12 subjects. Six subjects received the low dose, and a separate group of six subjects received the high dose. There was no change in the number of lines crossed $(A)$ or the number of rearings $(B)$. The time spent grooming $(C)$ increased during the 12 min test session after $20.0 \mu \mathrm{g}$ of alaproclate microinjection; * $p<0.05$ versus $0.0 \mu \mathrm{g}$.

Table 2. Regional extracellular 5-HT levels during reverse dialysis of alaproclate

\begin{tabular}{lcc} 
Alaproclate $(\mathrm{mm})$ & LHA $_{\mathrm{A}}$ 5-HT $(\mathrm{nM})$ & MPOA 5-HT (nM) \\
\hline 0.0 (basal) & $1.6 \pm 0.1$ & $1.4 \pm 0.1$ \\
0.978 & $13.8 \pm 3.6$ & $3.9 \pm 0.3$ \\
39.107 & $111.9 \pm 21.9^{*}$ & $39.6 \pm 13.7$ \\
78.214 & $185.2 \pm 37.7^{*}$ & $121.3 \pm 35.1^{*}$ \\
\hline
\end{tabular}

Values are means \pm SE for extracellular 5-HT levels in the $\mathrm{LHA}_{\mathrm{A}}$ and the MPOA after four doses of alaproclate perfusion via reverse dialysis. Alaproclate perfusion dose-dependently increased 5-HT levels. Basal extracellular levels of 5-HT in the $\mathrm{LHA}_{\mathrm{A}}$ were $1.6 \pm 0.1 \mathrm{~nm}$ and in the MPOA were $1.4 \pm 0.1 \mathrm{nM}$.

$* p<0.05$ versus basal.

lation, suggesting a role of 5-HT during the PEI (Mas et al., 1987; Fumero et al., 1994). However, Experiment 1b failed to show MPOA 5-HT increases during the PEI. Therefore, 5-HT release in the MPOA may have little or no role in the dynamic behavioral changes that occur during a copulatory series. The previously observed increases in 5-HIAA after ejaculation may be explained by intraneuronal breakdown of 5-HT, because 5-HT increases were not observed, or by diffusion from a nearby area, possibly the $\mathrm{LHA}_{\mathrm{A}}$.

The microinjection experiments also failed to support an inhibitory role for 5-HT in the MPOA. Alaproclate microinjections in Experiment $2 \mathrm{~b}$ increased the mean latency to initiate copulation, but the effect did not reach statistical significance. The discrepancy between the current data and previous studies may be explained by concentration and drug differences. Reports showing copulatory impairments were based on microinjections of 10-40 $\mu \mathrm{g}$ of 5-HT itself into the MPOA, a dose well above physiological levels. Reuptake inhibitors, on the other hand, rely on endogenous release to enhance extracellular levels of neurotransmitter; therefore, $20 \mu \mathrm{g}$ of alaproclate could not have produced the same increases in 5-HT as in these earlier reports. Indeed, the elevations in 5-HT produced by reverse dialysis of 20 $\mu \mathrm{g} / \mu \mathrm{l}$ alaproclate in Experiments $4 \mathrm{a}$ and $4 \mathrm{~b}$ (185 and $121 \mathrm{nM}$, respectively) would be the equivalent of $<40 \mathrm{pg} / \mu \mathrm{l}$. (Reverse dialysis of $20 \mu \mathrm{g} / \mu \mathrm{l}$ at $0.5 \mu \mathrm{l} / \mathrm{min} \times 10 \mathrm{~min} \times 25 \%$ probe recovery would have administered $\sim 25 \mu \mathrm{g}$ of alaproclate during the $10 \mathrm{~min}$ collection time.) The fact that $20 \mu \mathrm{g}$ of alaproclate produced significant effects when microinjected into the $\mathrm{LHA}_{\mathrm{A}}$, but not into the MPOA, suggests that the behavioral deficits produced by alaproclate are site-specific. Thus, there is little evidence that physiological levels or endogenous release of 5-HT in the MPOA contributes to the sexual refractoriness of the PEI.

Microinjections of alaproclate into the $\mathrm{LHA}_{\mathrm{A}}$ had no effect on forward locomotion. Therefore, a loss of general locomotor abilities is not sufficient to explain the delay in copulation observed during Experiment 2a, after microinjections of alaproclate. These observations suggest that, if enhanced 5-HT release in the $\mathrm{LHA}_{\mathrm{A}}$ regulates copulatory inhibition during the $\mathrm{PEI}$, it must do so through some mechanism other than simply impairing locomotion, which is normally absent or at least diminished during the PEI. Alternatively, 5-HT release after ejaculation may regulate physiological activities characteristic of the PEI that are not obviously related to copulatory deficits. For example, autonomic responses (e.g., blood pressure and heart rate) change dramatically at and after orgasm in humans (Masters and Johnson, 1966). Similar changes may occur in rats, and these may be regulated by the LHA. The insular cortex (important for autonomic control) projects to the LHA (Yasui et al., 1990), and blocking neurotransmitter release by injection of cobaltous chloride into the LHA attenuated insular-stimulated sympathetic responses (Cechetto and Chen, 1990). Whether 5-HT may be involved in these effects is not known.

The increase in time spent grooming after alaproclate administration was not predicted but is of interest. After ejaculation, males typically begin an intense bout of genital grooming. Microinjections of alaproclate increased primarily facial grooming, so it is difficult to relate this type of grooming enhancement to that seen after ejaculation. However, one may speculate that both types of grooming are regulated by similar central mechanisms, and that 5-HT in the $\mathrm{LHA}_{\mathrm{A}}$ may have a facilitative effect on grooming behaviors. Consistent with this idea, the satiety response after food intake includes facial grooming, which can also be elicited by stimulation of $5-\mathrm{HT}_{1 \mathrm{~B}}$ and $5-\mathrm{HT}_{1 \mathrm{C}}$ receptors (Kitchener and Dourish, 1994). In addition, a subset of dorsal raphe serotonergic neurons has been reported to increase activity during oral-buccal movements, including chewing, licking, and 
grooming (Fornal et al., 1996). This suggests that 5-HT release may increase in specific terminal regions during these behaviors. The LHA may be important for this response, because extracellular 5-HT activity increased in the LHA, concurrent with increased grooming (Aoyagi et al., 1992). Furthermore, electrical stimulation of the LHA has elicited facial and mouth grooming behaviors (Wayner, 1970; Singh et al., 1996), as well as stimulusbound ejaculation (Singh et al., 1996). It is not clear whether the behavioral deficits observed during copulation tests may have resulted from an increase in grooming behavior elicited by $5-\mathrm{HT}$ in the $\mathrm{LHA}_{\mathrm{A}}$.

In summary, extracellular 5-HT is increased in the $\mathrm{LHA}_{\mathrm{A}}$ during the PEI; no increases were observed at any other time during copulation or during a precopulatory exposure to an estrous female. Microinjections of the SSRI alaproclate increased the latency to mount, intromit, and ejaculate. Deficits in general locomotion cannot explain the copulatory impairments, because alaproclate microinjected into the $\mathrm{LHA}_{\mathrm{A}}$ did not affect either forward locomotion or number of rearings. Time spent grooming, on the other hand, increased. These effects were specific to the $\mathrm{LHA}_{\mathrm{A}}$. No 5-HT increases were observed in the MPOA at any time, and alaproclate microinjected into the same region did not produce copulatory impairments.

\section{REFERENCES}

Aoyagi K, Oomura Y, Shimizu N (1992) Concurrent measurement of serotonin metabolism and single neuron activity changes in the lateral hypothalamus of freely behaving rat. Behav Brain Res 49:205-212.

Bitran D, Hull EM (1987) Pharmacological analysis of male rat sexual behavior. Neurosci Biobehav Rev 11:365-389.

Cechetto DF, Chen SJ (1990) Subcortical sites mediating sympathetic responses from insular cortex in rats. Am J Physiol 258:R245-R255.

Fernandez-Guasti A, Escalante AL, Ahlenius S, Hillegaart V, Larsson K (1992) Stimulation of 5- $\mathrm{HT}_{1 \mathrm{~A}}$ and $5-\mathrm{HT}_{1 \mathrm{~B}}$ receptors in brain regions and its effects on male rat sexual behaviour. Eur $\mathrm{J}$ Pharmacol 210:121-129.

Foreman MM, Hall JL, Love RL (1989) The role of the 5- $\mathrm{HT}_{2}$ receptor in the regulation of sexual performance of male rats. Life Sci 45:1263-1270.

Fornal CA, Metzler CW, Marrosu F, Ribiero-do-Valle L, Jacobs BL (1996) A subgroup of dorsal raphe serotonergic neurons in the cat is strongly activated during oral-buccal movements. Brain Res 716:123-133.

Fumero B, Fernandez-Vera JR, Gonzalez-Mora JL, Mas M (1994) Changes in monoamine turnover in forebrain areas associated with masculine sexual behavior: a microdialysis study. Brain Res 662:233-239.

Glickman SE, Schiff BB (1967) A biological theory of reinforcement. Psychol Rev 74:81-109.
Gorzalka BB, Mendelson SC, Watson NV (1990) Serotonin receptor subtypes and sexual behavior. Ann NY Acad Sci 600:435-446.

Herman JB, Brotman AW, Pollack MH, Falk WE, Biederman J, Rosenbaum JF (1990) Fluoxetine-induced sexual dysfunction. J Clin Psychiatry $51: 25-27$.

Kitchener SJ, Dourish CT (1994) An examination of the behavioral specificity of hypophagia induced by $5-\mathrm{HT}_{1 \mathrm{~B}}, 5-\mathrm{HT}_{1 \mathrm{C}}$ and $5-\mathrm{HT}_{2}$ agonists using the post-prandial satiety sequence in rats. Psychopharmacology 113:369-377.

Kline MD (1989) Fluoxetine and anorgasmia. Am J Psychiatry 146:804-805.

Mas M, Rodriguez del Castillo A, Guerra M, Davidson JM, Battaner E (1987) Neurochemical correlates of male sexual behavior. Physiol Behav 41:341-345.

Mas M, Fumero B, Fernandez-Vera JR, Gonzalez-Mora JL (1995) Neurochemical correlates of sexual exhaustion and recovery as assessed by in vivo microdialysis. Brain Res 675:13-19.

Masters W, Johnson V (1966) Human sexual response. Boston: Little Brown.

Meisel RL, Sachs BD (1994) The physiology of male sexual behavior. In: The physiology of reproduction (Knobil E, Neill J, eds), pp 3-106. New York: Raven.

Morley JE, Levine AS, Gosnell BA, Mitchell JE, Krahn DD, Nizielski SE (1985) Peptides and feeding. Peptides 6[Suppl 2]:181-192.

Schwartz DH, McClane S, Hernandez L, Hoebel BG (1989) Feeding increases extracellular serotonin in the lateral hypothalamus of the rat as measured by microdialysis. Brain Res 479:349-354.

Singh J, Desiraju T, Raju TR (1996) Comparison of intracranial selfstimulation evoked from lateral hypothalamus and ventral tegmentum: analysis based on stimulation parameters and behavioural response characteristics. Brain Res Bull 41:399-408.

Verma S, Chhina GS, Kumar VM, Singh B (1989) Inhibition of male sexual behavior by serotonin application in the medial preoptic area. Physiol Behav 46:327-330.

Wayner MJ (1970) Motor control functions of the lateral hypothalamus and adjunctive behavior. Physiol Behav 5:1319-1325.

Wayner MJ, Barone FC, Laoullis CC (1981) The lateral hypothalamus and adjunctive behavior. In: Handbook of the hypothalamus, Vol 3, Part B (Morgane PJ, Panksepp J, eds), pp 107-146. New York: Dekker.

Wilson CA (1994) Pharmacological targets for the control of male and female sexual behaviour. In: Sexual pharmacology (Riley AJ, Peet M, Wilson CA, eds), pp 1-58. Oxford: Oxford Medical Publications.

Yasui Y, Breder CD, Saper CB, Cechetto DF (1990) Autonomic responses and efferent pathways from the insular cortex in the rat. J Comp Neurol 303:355-374.

Yells D, Prendergast M, Hendricks S, Nakamura M (1994) Fluoxetineinduced inhibition of male rat copulatory behavior: modification by lesions of the nucleus paragigantocellularis. Pharmacol Biochem Behav 49:121-127.

Zajecka J, Fawcett J, Schaff M, Jeffriess H, Guy C (1991) The role of serotonin in sexual dysfunction: fluoxetine-associated orgasm dysfunction. J Clin Psychiatry 52:66-68. 